UHERO

THE ECONOMIC RESEARCH ORGANIZATION AT THE UNIVERSITY OF HAWAI'I

\section{THE EFFECT OF PLAN B ON TEEN ABORTIONS: EVIDENCE FROM THE 2006 FDA RULING}

BY

INNA CINTINA AND MORGEN S. JOHANSEN

Working Paper No. 2014-1R

June 2014 
THE EFFECT OF PLAN B ON TEEN ABORTIONS: EVIDENCE FROM THE 2006 FDA RULING

\author{
Inna Cintina ${ }^{\dagger}$ and Morgen S. Johansen ${ }^{\ddagger}$
}

June 6, 2014

(Accepted for publication in Contemporary Economic Policy)

\begin{abstract}
An increase in the availability of emergency contraception (EC) may lead to a decrease in the abortion rate. The 2006 FDA ruling, which relaxed the prescription requirement for EC for women 18 and older, allows us to apply the difference-in-difference methodology on the age-by-year-by-state abortion data to test this hypothesis. Contrary to the literature, we find a moderate reduction in abortion rates among women aged 18 and 19 after 2006 in states that were affected by the change, compared to changes in the control group. These results are robust in a number of specifications and pass the event specification test. (J13, J18)
\end{abstract}

\footnotetext{
${ }^{\dagger}$ Corresponding author. University of Hawaii at Manoa, University of Hawaii Economic Research Organization, 2424 Maile Way, Saunders 540, Honolulu, HI 96822. Email address: icintina@hawaii.edu; Tel: (+1) 808-956-8791.

${ }_{\ddagger}^{\ddagger}$ University of Hawaii at Manoa, Public Administration Program and Public Policy Center, 2424 Maile Way, Saunders 405 Honolulu, HI 96822. Email address: morgen.johansen@hawaii.edu; Tel: (+1) 808-956-7551.

Acknowledgments: The authors are thankful for the helpful comments from the participants the 2013 Southern Economic Association Annual meetings as well Timothy Halliday, Jeffrey Traczynski, and Petru S. Stoianovici. Atsushi Shibata and Ben Trevino provided excellent research assistance.
} 


\section{INTRODUCTION}

In June 2013, the Food and Drug Administration (FDA) approved over the counter sales of Plan B One-Step, a single dose emergency contraceptive (EC) for women of all ages. The decision came after more than a decade of controversy and two years after the Health and Human Services director Kathleen Sebelius overruled the FDA decision and prevented Plan B from being sold over the counter across the country. ${ }^{1}$ Unplanned pregnancies impose high costs on women. Therefore, easy and timely access to EC can mitigate these costs.

Plan B, a well-known form of EC, has been available by prescription since 1999. It is an effective and relatively cheap way to avoid unintended pregnancy when other forms of birth control fail, or when birth control is not used. In 2006, the FDA lifted the EC prescription requirement for women 18 years of age or older; those 17 and younger, on the other hand, still required a prescription. The need for a prescription is particularly salient since Plan B works best when it is taken as soon as possible after unprotected sex, and any delays in access lower its efficacy rate. A clear age cut off set by the ruling decreases costs associated with sexual behavior for some young women relative to other young women, and can be exploited to identify a differential response to increased EC access across these two groups.

Unlike most related studies that rely on differences across locations, we use a variation in EC availability across age groups to identify a link between changes in access and fertility behavior measured with abortion rates. The policy set up (i.e., age differentiation) allows us to improve upon the existing literature by utilizing single age by year data on abortions instead of 5-year age group aggregates commonly used in economic studies. There are likely to be cost differences within the aggregated age groups since available resources, housing options, independence level, and overall financial situation varies as one progresses from age 15 to 19 . Over time, the cost differences across groups can be affected by policy changes, such as the prescription elimination in August 2006 that affected only 18 and 19 year old women. If the change in costs is sufficient, we would expect measurable differences in abortion rates in the years after the policy change.

Using a difference-in-difference methodology, where women aged 15, 16, and 17 are treated as a control group, and focusing on states that were affected by the FDA policy change,

\footnotetext{
${ }^{1}$ The decision was made for political reasons and not medically based (Wood, Drazen and Greene 2012, Price 2011).
} 
we find a considerable reduction in abortion rates among women aged 18-19 in the years following the FDA's announcement in 2006, compared to changes in the control group. The relative magnitude of change associated with the elimination of the prescription requirement ranges from 8-9\% (or 1.6-1.8 abortions per 1,000 women). However, the magnitude, to some extent, is driven by a substantially large change in abortion rates among "treated" women in 2010. The exclusion of 2010 yields a more conservative estimate of 6\%, or 1.2-1.3 abortions. We do not observe a similarly large reduction in abortion rates in the post-policy years among women aged 20-24. After adjusting for a small number of clusters, we also fail to reject the null of zero effect for this age group. Further disaggregation of women aged 18-19 into two separate age groups indicates that the effect might be concentrated among women aged 18. The magnitude of the effect, to some degree, is sensitive to the choice of the control group (age 15 or 16), and the use of population weights. All estimated models pass the event-study specification test. Our estimation strategy also passes the falsification test.

The results reported here are in contrast to Gross et al (2013), who conclude that the change in the FDA's policy does not affect abortion rates among women under the age of 20. Differences in results might be due to differences in empirical strategies. We use across age variation in cost differences for young women in states that were affected by the change, whereas Gross et al utilize across state differences in costs, effectively comparing abortion rates in states that were not affected by the FDA announcement (i.e. pharmacy EC access states) and states that were affected by the change. The latter strategy does not take advantage of the cost variation within the 15-19 age group created by the FDA policy.

\section{MECHANISMS LINKING ACCESS TO EC AND FERTILITY RATES}

There are two competing mechanisms that link access to EC and abortion rates. First, other things being constant, lower costs of EC and/or easier access to EC should increase its use, resulting in fewer unwanted pregnancies and hence lower abortion rates (as unwanted pregnancies are more likely to be terminated). Such a change in unwanted fertility rates is conditional on the assumption that women are aware of the effectiveness of EC and its availability, and actually use it. Research finds that young adults aged 18-24 are aware of EC (Baldwin et al 2008), can use it correctly (Glasier and Baird 1998), and that easier access to EC increases its use (Glasier et al 2004, Raine et al 2000). The elimination of a prescription 
requirement makes access to EC easier, and reduces the overall cost of obtaining EC, particularly by lowering the financial cost. ${ }^{2}$

However, despite changes in EC use rates due to easier access, there is limited evidence in the literature in favor of a negative relationship between easy EC access and abortion rates. In a study focused on across county variation in access to EC within Washington state, Cintina (2014) finds that increased access to EC is associated with a statistically significantly decrease in the abortion rate among young women in the affected counties. However, the economic effect associated with a presence of no-prescription EC pharmacies is rather small and does not affect abortion rates substantially. ${ }^{3}$

An alternative mechanism is that, in response to easier access to EC, young adults may increase sexual risk taking (e.g., sex without contraception) because they know that the cost of unplanned pregnancy has decreased. This scenario is conditional on the assumption that young adults know about the changes in the legislation and take them into account while making decision regarding risky sex. In this case, if women take EC after unprotected intercourse to avoid an unplanned pregnancy, the change in fertility rates associated with changes in sexual behavior should not be substantial. The effect (if any) will be driven by factors associated with the effectiveness and correct usage of the pills (EC is not $100 \%$ effective and needs to be taken within a narrow time frame). However, if young adults on average are not forward looking and risky sex occurs on the spur of the moment, then there should not be substantial changes in risk taking.

Research produces mixed results with respect to the link between EC and increase in risky sexual behavior. For example, Girma and Paton (2011) and Durrance (2013) find that increased access to EC increases sexually transmitted disease (STD) rates, which are used as a proxy for risky sexual behavior. Paton (2006) finds that free access to EC at pharmacies is positively associated with sexually transmitted infection (STI) diagnoses, but the statistical power of results varies across models depending on a deflator used for a family planning

\footnotetext{
${ }^{2}$ Marciante et al (2001) find that, depending on the model, the cost savings associated with obtaining EC at a pharmacy without a prescription could vary between $\$ 50$ for a public payer and $\$ 160$ for a private payer.

${ }^{3}$ Oza (2009) also found a decrease in abortions among 15-29 year-old women due to the FDA's policy change in 2006. However, abortion rates in Oza's dataset are greatly understated, and the claimed $37.2 \%$ magnitude reflects the peculiarity of the insurance claims data used in the analysis.
} 
measure, which is also included in the model. In contrast, a number of advanced provision randomized control trial studies do not find evidence of increased risk taking, as measured by sexual activity, use of contraception, and risk of STDs (Gold et al 2004, Harper et al 2005, Raine et al 2005, Stewart et al 2003).

Regardless of these mixed findings about behavior change and EC, the literature that relies on geographical variation in EC availability consistently reports that neither abortion, nor birth and pregnancy rates are statistically significantly affected by an increase in EC access (Durrance 2013, Gross et al 2013, Girma and Paton 2011, Paton 2006, Paton 2002). Similarly, studies based on small-scale randomized control trials also do not find differences in abortion rates as a result of easy access to EC (Glasier et al 2004, Raine et al 2005). ${ }^{4}$

\section{DATA}

The age restriction embodied in the FDA ruling allows us to employ a difference-indifference (DID) methodology, where women aged 17 and younger serve as a control group and those older than 17 as a treatment group. We use state level abortion data from the 2000-2010 Abortion Surveillance Reports to construct annual state level abortion rates by single year of age for 15 to 19 year old women, and abortion rates aggregated into age groups: 15-16, 15-17, 18-19, and 20-24 year old women. ${ }^{5}$

The estimates based on these abortion rates are likely to be underestimated due to a lack of uniform reporting requirements of abortions across states. Some states do not report abortions by single year of age, or do not report them at all or on a continuous basis. ${ }^{6}$ Appendix A shows the geographical variation in data availability. Additionally, the District of Columbia (DC), Delaware, Iowa, and New Jersey were removed from the dataset due to changes in the reported statistics during the study period. The constructed panel contains the abortion rates for 41 states.

Abortion data are recorded by state of occurrence and not by state of residence. The latter would be more preferable as it is not biased by the interstate mobility of women who may try to

\footnotetext{
${ }^{4}$ To our knowledge, one randomized control trial study (Shaaban et al 2013) finds that the use of EC pills, as a backup plan for the lactation amenorrhea method, decreases the incidence of unplanned pregnancy during breastfeeding.

${ }^{5}$ We also consider women aged 25-29, but this age group did not pass the event-specification test, indicating that women aged 15 to 17 are not a good control group for the 25-29 age group. ${ }^{6}$ In a few cases, when a single year of data was missing, we used a linear interpolation or, where available, supplemented data with statistics from the state's Vital Statistics Reports.
} 
avoid restrictions that limit the availability of reproductive health services (including abortion) locally by obtaining an abortion in a state with less rigorous restrictions (e.g., parental involvement laws for minors' abortion). However, since we focus on the federal change that affected all states, rather than changes in state laws, the occurrence data is less of a concern.

Seven states in our dataset allowed women of any age to access EC at pharmacies without a prescription in certain settings prior to August 2006 (pharmacy access states). ${ }^{7}$ We exclude pharmacy access states from the DID analysis as they might differ considerably from the non-pharmacy access states. Figure 1, which shows abortion rates by age group and pharmacy access status, confirms that abortion rates in all age groups are generally higher in states with the relaxed prescription requirement for EC, and, in some cases, trends in the pre-2007 period are substantially different across the two sets of states. Therefore, the exclusion is appropriate.

Since pharmacy access states do not have an age restriction, "border hopping" with respect to EC may affect abortion rates in the neighboring states. However, it is likely that only women who live in close proximity to the state border (and hence are relatively close to a noprescription EC pharmacy) may be willing to do so as the overall cost, which includes driving time, increases with the distance to the closest no-prescription EC pharmacy. Therefore, for a relatively large share of women, it might be faster and more efficient to get a prescription and buy EC locally. There is not strong evidence of border hopping from Idaho and Oregon to Washington, the first state to allow the no-prescription access to EC in 1998 (Cintina 2014). Thus, it is unlikely that the overall aggregate state abortion rate will be affected substantially by the mobility factor, and the use of abortion data by occurrence is acceptable.

The average abortion rates for various ages are reported in Table 1. It appears that abortion rates have decreased in all age groups after 2006, with slightly larger changes among women younger than 18. For example, the abortion rate among women aged 15-17 decreased from 7.7 abortions to 6.2 abortions per 1,000 women, representing a change of nearly 20\%. For women aged 18-19 there was a reduction of about $17 \%$, and a substantially smaller change of $10 \%$ among women aged 20-24. The question is whether these differences in abortion rates are statistically significant after controlling for state specific time invariant and time variant socioeconomic characteristics.

${ }^{7}$ These states are Alaska, Hawaii, Massachusetts, Maine, New Mexico, Vermont, Washington. 


\section{METHODOLOGY}

To identify whether changes can be attributed to a change in the FDA policy, we start with a baseline DID model given by:

$$
Y_{g s t}=\beta_{0}+\beta_{1} A G E 1819_{g}+\beta_{2} A F T E R_{t}+\beta_{3}\left(A G E 1819^{*} A F T E R\right)_{g t}+\gamma X_{g s t}+\lambda_{s}+\varepsilon_{g s t},
$$

where $g$ indexes age groups, $s$ indexes states, and $t$ indexes years 2000 through 2010.

The dependent variable, $Y_{g s t}$, is the abortion rate per 1,000 women in the corresponding age group $(g)$ in a state-year $(s t)$. An indicator, $A G E 1819$, separates the control group, women aged 15-17, and the treatment group, women aged 18-19. The variable AFTER indicates the postFDA ruling time period 2007-2010. ${ }^{8}$ The overall effect of the 2006 FDA ruling on abortion rates among relatively older women, compared with the changes in the abortion rate among relatively younger women, is given by $\beta_{3}$. If easier access increases the use of EC and reduces the incidence of unwanted pregnancies, then the abortion rate will decline, implying a negative $\beta_{3}$. If easier access encourages risky sexual behavior and non-use of contraception, leading to a higher rate of unplanned pregnancies, the abortion rate among affected older women may increase, implying a positive $\beta_{3}$. The latter situation would be observed when a higher incidence of unplanned pregnancy is not entirely offset by the increased use of EC.

The vector $X_{g s t}$ includes the state unemployment rate among females by age group, real per capita personal income, the maximum Aid to Families with Dependent Children (AFDC) benefit level for a family of three, and an indicator for the enforced parental involvement (PI) laws, notification and/or consent for minors. ${ }^{9}$ The latter variable is set to zero for all ages other than 15 to 17 , as the laws affects only under-aged teens. If the policy was enforced for only part of a year, then this variable indicates the fraction of the year the policy was in effect. Additionally, we include a control for border state PI policies, approximated by the number of neighboring states that either have no PI or have enjoined (unenforced) PI laws. The descriptive statistics of the variables included in the model are reported in Table 1.

The availability of reproductive services in a state is an important determinant of the overall demand for abortion services. However, there are almost no changes in the state per

\footnotetext{
${ }^{8}$ EC in new packages that reflected the policy change was not available until November 2006. Therefore, we do not expect to observe changes in abortion rates earlier than 2007.

${ }^{9}$ The corresponding data sources are the Bureau of Labor Statistics, the Bureau of Economic Analysis, the Urban Institute's welfare database, the Alan Guttmacher Institute's (AGI) State Policy Briefs, and Myers (2012).
} 
capita number of abortion providers between 2000 and 2010. ${ }^{10}$ Since the within state variation across time is very limited, the state specific effects should account for the effect of the number of abortion providers in the state. Finally, $\lambda$ in equation (1) represents a vector of state fixed effects that captures all time invariant factors that affect abortion rates in the state.

To analyze the timing of effects, we introduce a set of interaction terms between the treatment indicator and each year dummy ranging from 2007 to 2010 instead of the $A G E 1819^{*} A F T E R$ term (we also add a full set of year fixed effects instead of a dichotomous measure, AFTER). Then, equation (1) is estimated for an alternative treatment group, women aged 20-24. It is expected that the effect on the 18-19 age group will be larger than on the 20-24 age group as older women are likely to have more resources, be more independent, and less concerned about their parents finding out about a visit to a doctor for an EC prescription. We also test the sensitivity of the results to the inclusion of state-specific linear trends and the use of population weights. ${ }^{11}$ Additionally, for both equation (1) and its variation with the dynamic effects, we analyze residuals to identify whether there are age-specific trends that are not captured by these models. Based on the inspection of age-specific residual plots and the regression analysis, where age-specific residuals are regressed on a linear trend, we conclude that in the vast majority of model-specification combinations, the variation in the residuals cannot be explained by a linear trend (results are not reported here, but are available upon request).

The identification of the DID model relies on the assumption that abortion rates for both the treatment and control group have similar trends in the pre-treatment period, implying that in the absence of the treatment the average changes in abortion rates would be similar for both groups. We test the appropriateness of the DID model by estimating an event-study specification that allows for an unrestricted examination of the differences in the rates between the treatment and control groups in the years prior to and after the 2006 FDA ruling. The inclusion of the full set of interaction effects between age and year also allows for a flexible parameterization of the age-specific time trends. If the model is correct, the estimated coefficients for the interaction terms between the treatment dummy and each year in the period 2000-2005 should be small and

${ }^{10}$ Data on abortion providers by state are available for selected years only from the AGI.

${ }^{11}$ An alternative model, with a full set of state by year dummies, produces similar results. However, these specifications generally had a lower adjusted R-square. 
statistically insignificant, relative to the FDA's ruling year (the omitted year). The event-study specification is given by:

$$
\begin{aligned}
Y_{g s t}=\beta_{0}+\sum_{k=2000}^{2005} & \eta_{k}\left(A G E 1819_{g} * Y E A R_{k}\right)+\sum_{l=2007}^{2010} \mu_{l}\left(A G E 1819_{g} * Y E A R_{l}\right)+ \\
& +\beta_{1} A G E 1819_{g}+\gamma X_{g s t}+Y E A R_{t}+\lambda_{s}+\varepsilon_{g s t},
\end{aligned}
$$

where notation follows equation (1) notation. Additionally, $Y E A R$ is a vector of time fixed effects that captures factors that are common across all states in a given time period (omitted year 2006). Similar to the DID model above, seven pharmacy access states were excluded from the sample. The sensitivity analysis includes the use of an alternative treatment group (women aged 20-24), the inclusion of state-specific linear trends, and population weights.

The easy availability of EC for women age 18 and older may have a "spillover" effect on younger women. This might be plausible in situations when younger women obtain EC with the help of their older friends, who are exempt from the prescription requirement. If such behavior is typical, 17 year olds may not be an appropriate control group. ${ }^{12}$ We investigate the robustness of our model by restricting the control group to women aged 15-16 and by introducing a single year of age control group (i.e., separate models for control groups: age 15, age 16, and age 17) instead of the aggregated age group of 15-17. These regressions are implemented similarly to equations (1) and (2) with the addition of separate age indicators and respective interaction terms for each age group (age 18 and age 19) instead of aggregated $A G E 1819$.

Finally, we perform a falsification test by limiting data to 2000-2006 and assigning a “treatment event” to occur in 2003. Given a hypothetical nature of this treatment event, we should not observe significant differences in abortion rates between 15-17 and 18-19 year old women in the "post-treatment" period. ${ }^{13}$

\footnotetext{
12 Additionally, in July 2009, the FDA updated the age requirement to 16 years and younger, switching the status of 17 year olds from the control group to the treatment group.

${ }^{13}$ For a second falsification test, we attempted to utilize pharmacy access states. In these states neither women aged 15-17, nor older women, are affected by the FDA's ruling as everyone, regardless of their age, already have access to EC without a prescription. Therefore, one should not see a statistically significant change in abortion rates among women aged 18 and 19 after 2006 relative to a change in the control group. To account for differences in the timing of implementation of state laws, and to ensure the comparison of women who had no age restriction to EC access prior to 2006 to women who had no age restrictions to EC after 2006, the data prior to 2006 was limited to years when the pharmacy access laws were actually in effect (a similar strategy is used in Gross et al 2013 who limit their pre-2007 years to 2004-2006). The resulting unbalanced panel is too small to obtain reliable estimates.
} 


\section{RESULTS}

\section{A. Baseline DID Model Results}

Results for the DID model are reported in Table 2. Panel A corresponds to equation (1); Panel B shows the results from a model that allows for dynamic changes in the years after 2006; Panel C corresponds to the model in Panel B with an alternative treatment group, women aged 20-24. For each panel, specification (1) is treated as a baseline model. Specification (2) includes the state-specific linear trends. In specification (3), in addition to trends, observations are weighted by the state's female population in the appropriate age group. We generally focus our discussion on the specifications with trends as those are consistent with the literature. We should note that the inclusion of weights, warranted by the data, consistently yields the largest point estimates for the policy effects. Standard errors are clustered at the state level. However, in the presence of a small number of clusters (e.g., 34 states), the cluster-robust standard errors are downward biased leading to the over-rejection of the null in the standard tests. We implement a wild cluster bootstrap-t (bootstrap-t) procedure with 1,000 repetitions suggested by Cameron et al (2008) and report the corresponding p-values for the variables of interest. This procedure does not adjust standard errors per se, but allows us to estimate the empirical distribution of t-statistics under the null, which substantially improves the quality of inference. ${ }^{14}$

Results from Panel A-1 indicate a moderate and statistically significant reduction in the abortion rate among women aged 18-19 in the years after the FDA's ruling. The abortion rate decreased by 1.6 abortions per 1,000 women aged $18-19$, relative to the change in the control group. This corresponds to an $8 \%$ reduction in the pre-2007 average abortion rate of 20.5 abortions per 1,000 women aged 18-19. The inclusion of population weights and trends (Panel A-3) increases the point estimates for the effect of the FDA's ruling on 18-19 year old women, but does not substantially alter the relative magnitude: the decrease in the abortion rate becomes 8.6\% (the bootstrap-t p-value is 0.002). However, the use of weights inflates the estimate for the enforced PI laws, indicating a rather large, positive effect. One should keep in mind that between

\footnotetext{
${ }^{14}$ As an additional robustness check, we also consider clustering at the age level for models that use the single year of age data. The results reported in Appendix B (Panel A) show a statistically significant decrease in the abortion rate among women aged 18 in the post-policy years (specifically in 2008-2009). Yet, these results are sensitive to the inclusion of population weights, which generally reduce the statistical power of the estimates. Although simulations presented in Cameron et al (2008) show that the method works reasonably when there are five clusters, they note that the power of the test increases as the number of clusters increases.
} 
2000 and 2010 all but four states in our sample (Arizona, Colorado, Idaho, and Oklahoma) either enforced PI laws during the entire period, or did not have or enforce them. The limited withinstate variation underpowers the PI's estimate, affecting its credibility. The unemployment rate among women has a negative effect on the abortion rate, although the point estimate lacks the statistical significance in the model with trends. The effects of other state level socio-economic variables are generally numerically small with relatively large standard errors, possibly reflecting limited within-state variation.

The simple indicator for the after period does not provide information about the dynamics of changes. The results from Panel B-1 show a lagged change in the abortion rate. ${ }^{15}$ In 2007, the estimate for women aged 18-19 was only marginally statistically different from the change in the control group (bootstrap-t p-value 0.096). In contrast, the decreases in the abortion rate after 2007 were statistically significant: a 4\%, 10\%, and 14\% change relative to the pre-2007 average, respectively in 2008, 2009, and 2010. The addition of population weights and trends increases these estimates by about one percentage point, but does not substantially alter the statistical power of the estimates even after a correction for a small number of clusters. A relatively large effect in 2010 (a decrease of 3 abortions) might be driven by the additional increase in affordability of EC due to the FDA's approval of the generic version of Plan B in late 2009, and media coverage of changes in the FDA policy for women aged 17 in the same year. The data on Plan B sales, reported in Gross et al (2013), also supports the idea of a gradual increase in the awareness of EC pills over time (e.g., between 2006 and 2009, sales of Plan B quadrupled to a level of about 68,000 units sold per week). Given a range of effects over the post-policy years, the overall effect reported in Table 2, Panel A, to some extent, reflects that large change in 2010. The exclusion of 2010 yields estimates of a much smaller magnitude: an overall reduction of 1.21.3 abortions per 1,000 women aged 18-19 (or 6\%) in the post-policy years.

Panel C reveals that the effect on women aged 20-24 is generally not statistically significant. In the economic sense, with the exception of 2009-2010, the point estimates are also

${ }^{15}$ Delays in information dissemination are possible. Based on a survey conducted in 2003, Salganicoff et al (2004) note that only $18 \%$ of teens and adults of reproductive age in California knew about the EC pharmacy access policy, which was enacted in 2002. Additionally, television appears to be the primary source of information among those who heard about EC. Survey data from Massachusetts, which passed similar legislation in 2005, suggests that there was no significant difference in the number of women aged 18-44 who had heard of EC between 2006 and 2008 (MDPH, 2010). 
rather small. The lack of substantial differences in the abortion rates among women aged 20-24 in the post-policy years is not surprising. We expected to observe a relatively smaller effect, compared to women aged 18-19, due to potential differences in behavior as well as the costs of obtaining EC across age groups (with younger women facing higher costs and therefore benefiting more from the change). The results confirm these differences.

\section{B. Event Specification Test Results}

As noted earlier, the credibility of our DID models depends on the assumptions regarding the behavior of women in the control and treatment groups. Figure 2 shows estimates for the interaction terms between the treatment group, age 18-19, and year dummies, with the corresponding 95\% confidence intervals. ${ }^{16}$ The model also includes a set of state-level socioeconomic characteristics, state and year fixed effects, and state-specific linear trends. Observations are weighted by the state's female population in the respective age group.

The event-study specification confirms the appropriateness of the DID model: the 95\% confidence interval is wide, none of the estimates for the period prior to the FDA's policy change are statistically different from zero at the conventional level of significance, and we do not observe a distinct downward trend in the years prior to 2007. Since clustering when the number of clusters is small underestimates standard errors, not finding an effect when clustering at the state level corresponds to a more conservative approach in ruling out a pre-existing trend. We confirm the validity of these results with the bootstrap-t p-values (we fail to reject the null of zero effect at the $10 \%$ level of significance for all interaction terms in the pre-2007 period). Further restricting the control group to women aged 15-16, instead of 15-17, yields qualitatively similar results (albeit with slightly larger point estimates). Similarly, the DID model with an alternative treatment group, women aged 20-24 (Figure 3), also passes the specification test. However, for nearly all years, we fail to reject the null of zero effect using the bootstrap-t method (exceptions are 2009 and 2010 where estimates are marginally statistically significant).

Next, we investigate the effects by single year of age. This strategy allows us to more precisely identify the age groups affected by the change in EC availability. Table 3 shows effects separately for women aged 18 and 19 relative to changes in the control group represented by women aged 15 and 16. Results indicate that numerically, the effect is slightly larger for women

${ }^{16}$ The point estimates for all specifications of the event-study models are available upon request. 
aged 18. In the 2007-2010 period, the abortion rate among women aged 18 decreased by about 2 abortions per 1,000 women, or 11\% compared to the average abortion rate for women in this age group in the pre-policy years (Panel A-3). The corresponding change for women aged 19 was $8 \%$. Statistically, both estimates are different from zero even after the correction for the small number of clusters. The exclusion of data for 2010 yields more conservative estimates of $8 \%$ and $6 \%$ respectively.

Further analysis of timing, reported in Panel B, reveals the existence of substantial differences in responses across age groups. For example, among women aged 18, a marginally statistically significant decrease of 5\% in the abortion rate is observed as early as 2007 (Panel B2). Although the addition of population weights slightly decreases the magnitude, the corresponding estimate of the p-value from the wild cluster bootstrap-t is larger (0.108 instead of 0.054). By 2010, the statistically significant effect gradually increases to a range of a $17-20 \%$ reduction in the abortion rate relative to the pre-2007 average depending on the specification. In contrast, changes in the abortion rate among women aged 19 are smaller and generally more imprecise; we consistently fail to reject the null of zero effect in 2007-2008. These results are also robust for the event-study test (Figure 4). The inclusion of the full set of interaction terms decreases the magnitude of the estimates on the post-policy year interaction terms and improves model fit. Similar to age 18, the effect on age 19 is rather large in 2009 and 2010.

\section{Robustness Checks and Falsification Test Results}

Finally, to test the sensitivity of the results to the definition of the control group, we estimate a series of models where the control group is restricted to a single year of age (i.e., separate models for the age 15, age 16, and age 17 control groups). Figure 5, Panel A shows the point estimates for the interaction terms with the corresponding 95\% confidence intervals for a model with the age 15 control group. Panel B shows the corresponding estimates for the age 16 control group. ${ }^{17}$ The relative magnitude of an overall reduction in the abortion rate after the FDA's policy change among women aged 18 ranges from 13\% in models where the control group is restricted to 15 year old women, to $9 \%$ in models where the control group is women aged 16. In both cases, the effect for years 2007-2010 is statistically different from zero. The magnitude of change among women aged 19 exhibits a similar pattern (a decrease of $10 \%$ and

\footnotetext{
${ }^{17}$ A model with the age 17 control did not pass the event-specification test.
} 
7\% for the control groups age 15 and age 16, respectively).

The research design also passes the falsification test. The overall change in the abortion rate among women aged 18-19 in 2004-2006, relative to change in the abortion rate among women aged 15-16, is relatively small (the point estimate is -0.7) and statistically insignificant (bootstrap-t p-value 0.254). The estimate is qualitatively similar, but smaller, when compared to the aged 15-17 control group. Figure 6 shows that the dynamic changes in abortion rates after the hypothetical treatment are not economically and statistically different from changes in the control group. None of the estimates for the interaction terms are statistically different from zero at the $8 \%$ significance level. Similarly, in the specification without weights, we fail to reject the null of zero effect at the $10 \%$ level. We do not evaluate the bootstrap-t p-values for this model since not finding an effect when clustering at the state level is a more conservative way of ruling out of the effect of the hypothetical treatment. Slightly less robust estimates are observed for the disaggregated 18 and 19 age groups (Panel B).

Finally, it can be argued that state level data used for the analyses artificially increases the sample size as the policy measured varies by age and year rather than by state and year. Panel $\mathrm{B}$ in Appendix B shows the most conservative set of results from a panel dataset, where the unit of observation is the average abortion rate in a given age-year. Although this set-up substantially reduces the number of observations, it still permits estimation of a basic DID model. These results confirm a statistically significant decrease in the abortion rate among older women relative to women younger than age 18 in the post-policy years.

\section{CONCLUSION}

Unintended pregnancy is a substantial public health concern in United States. According to data from the National Survey of Family Growth, nearly half of all pregnancies in 2006 were unintended (Finer and Zolna 2011). The consequences of unintended pregnancy are especially high for teenagers as childbearing at a young age can lead to an inferior education and fewer earnings in the future. Changes in access to contraception including EC can reduce unintended pregnancies. For a long time, easy and timely access to EC was obstructed by a requirement to have a doctor's prescription. Given that the efficacy rate of EC is inversely related to time passed since unprotected intercourse, the prescription requirement can make EC less effective, thereby increasing the overall cost of obtaining EC. In 2006, the FDA removed the prescription 
requirement for women older than age 17 . The age restriction was placed in part due to concerns about the potential for irresponsible sexual behavior in teenage girls. Given the mixed results reported in the literature on the link between easy access to EC and sexual risk taking, the analysis of consequences of easy access to EC for teenagers is critical.

We use the 2006 change in the FDA policy, which relaxed the prescription requirement for women aged 18 and older, to test whether the incidence of unintended pregnancies changed among the affected population (i.e. women aged 18 and aged 19 in states subject to the FDA policy change) compared to women in the same states for whom costs did not change (i.e. women 15, 16, and 17). We hypothesize that, in the absence of behavioral changes in sexual risk taking, we should observe a decrease in abortion rates among women aged 18 and aged 19 in the years following 2006 relative to changes in abortion rates among women aged 15, 16, and 17.

Our results suggest that increased access to EC does not promote irresponsible sexual behavior among young women, as we find a moderate decrease in abortion rates among young women for whom the FDA policy change reduced the cost of EC access. Additionally, this research suggests that the 2006 FDA policy, which increased access to EC, had a differentiated effect on young women and that this effect could not be easily identified using aggregated data on abortion rates.

\section{REFERENCES}

Baldwin, S. B., R. Solorio, D. L. Washington, H. Yu, Y. Huang, E.R. Brown. "Who is Using Emergency Contraception? Awareness and Use of Emergency Contraception Among California Women and Teens.” Women's Health Issues, 18, 2008, 360-68.

Cameron, A. C., J. B. Gelbach, and D. L. Miller. “Bootstrap-Based Improvements for Inference with Clustered Errors”, Review of Economics and Statistics, 90(3), 2008, 414-427.

Cintina, I. "Behind-the-counter, but Over-the-border? The Assessment of the Geographical Spillover Effect of Increased Access to Emergency Contraception.” Working paper, 2014. Durrance, C. P. “The Effects of Increased Access to Emergency Contraception on Sexually Transmitted Disease and Abortion Rates. Economic Inquiry, 51(3), 2013, 1682-95.

Finer L. B., and M. R. Zolna. “Unintended Pregnancy in the United States: Incidence and Disparities, 2006. ”Contraception, 84(5), 2011, 478-85. 
Girma, S., and D. Paton. “The Impact of Emergency Birth Control on Teen Pregnancy and STIs.” Journal of Health Economics, 30(2), 2011, 373-80.

Glasier, A., and D. Baird. “The Effects of Self-Administering Emergency Contraception.” The New England Journal of Medicine, 339(1), 1998, 1-4.

Glasier, A., K. Fairhurst, S. Wyke, S. Ziebland, P. Seaman, J. Walker, and F. Lakha. “Advanced Provision of Emergency Contraception Does Not Reduce Abortion Rates.” Contraception, 69, 2004, 361-66.

Gold, M. A., J. E. Wolford, K. A. Smith, and A. M. Parker. "The Effects of Advance Provision of Emergency Contraception on Adolescent Women’s Sexual Behaviors.” Journal of Pediatric and Adolescent Gynecology, 17(2), 2004, 87-96.

Gross, T., J. Lafortune, and C. Low. "What Happens the Morning After? The Costs and Benefits of Expanding Access to Emergency Contraception.” Journal of Policy Analysis and Management, 33(1), 2013, 70-93.

Harper, C. C., M. Cheong, C. H. Rocca, P. D. Darney, and T. R. Raine. “The Effect of Increased Access to Emergency Contraception among Young Adolescents.” Obstetrics and Gynecology, 106(3), 2005, 483-91.

Massachusetts Department of Health. “A Profile of family Planning Among Massachusetts Adults 2006-2008. Results from the Behavioral Risk Factor Surveillance System.” 2010.

Marciante, K. D., J. S. Gardner, D. L. Veenstra, and S. D. Sullivan. “Modeling the Cost and Outcomes of Pharmacist-Prescribed Contraception.” American Journal of Public Health, 91(9), 2001, 1443-45.

Myers, C. K. "Power of the pill or power of abortion? Re-examining the effects of young women's access to reproductive control.” The Institute for the Study of Labor Discussion Paper No. 6661, 2012.

Oza, A. "Plan B as Insurance: The Effect of Over-the-Counter Emergency Contraception on Pregnancy Terminations and STIs”. Working Paper, 2009.

Paton, D. “The Economics of Family Planning and Underage Conceptions.” Journal of Health Economics, 21(2), 2002, 207-25. "Random Behavior or Rational Choice? Family Planning, Teenage Pregnancy and STIs.” Sex Education: Sexuality, Society, and Learning, 6(3), 2006, 281-308. 
Price, K. “The Quest for Purity: The Role of Policy Narratives in Determining Teen Girls’ Access to Emergency Contraception in the USA.” Sexuality Research and Social Policy, 8(4), 2011, 282-93.

Raine, T. R., C. C. Harper, K. Leon, and P. D. Darney. “Emergency Contraception: Advanced Provision in a Young, High-Risk Clinic Population.” Obstetrics and Gynecology, 96(1), 2000, $1-7$.

Raine, T. R., C. C. Harper, C. H. Rocca, R. Fischer, N. Padian, J. D. Klausner, and P. D. Darney. "Direct Access to Emergency Contraception through Pharmacies and Effect on Unintended Pregnancy and STIs.” Journal of the American Medical Association, 293(1), 2005, 54-62.

Salganicoff, A., B. Wentworth, and U. Ranji. "Emergency Contraception in California: Findings from a 2003 Kaiser Foundation survey.” Henry J. Kaiser Family Foundation report, 2004.

Shaaban, O. M., S. G. Hassen, S. A. Nour, M. A. Kames, and E. M. Yones. “Emergency Contraceptive Pills as a Backup for Lactational Amenorrhea Method (LAM) of Contraception: A Randomized Controlled Trial.” Contraception, 87(3), 2013, 363-69.

Stewart, H. E, M. A. Gold, and A. M. Parker. “The Impact of Using Emergency Contraception on Reproductive Health Outcomes: A Retrospective Review in an Urban Adolescent Clinic.” Journal of Pediatric and Adolescent Gynecology, 16(5), 2003, 313-18.

Wood, A. J, J. M. Drazen, and M. F. Greene. “The Politics of Emergency Contraception.” The New England Journal of Medicine, 366(2), 2012, 101-102. 


\section{FIGURE 1}

Trends in aggregate abortion rates by age group and pharmacy access status
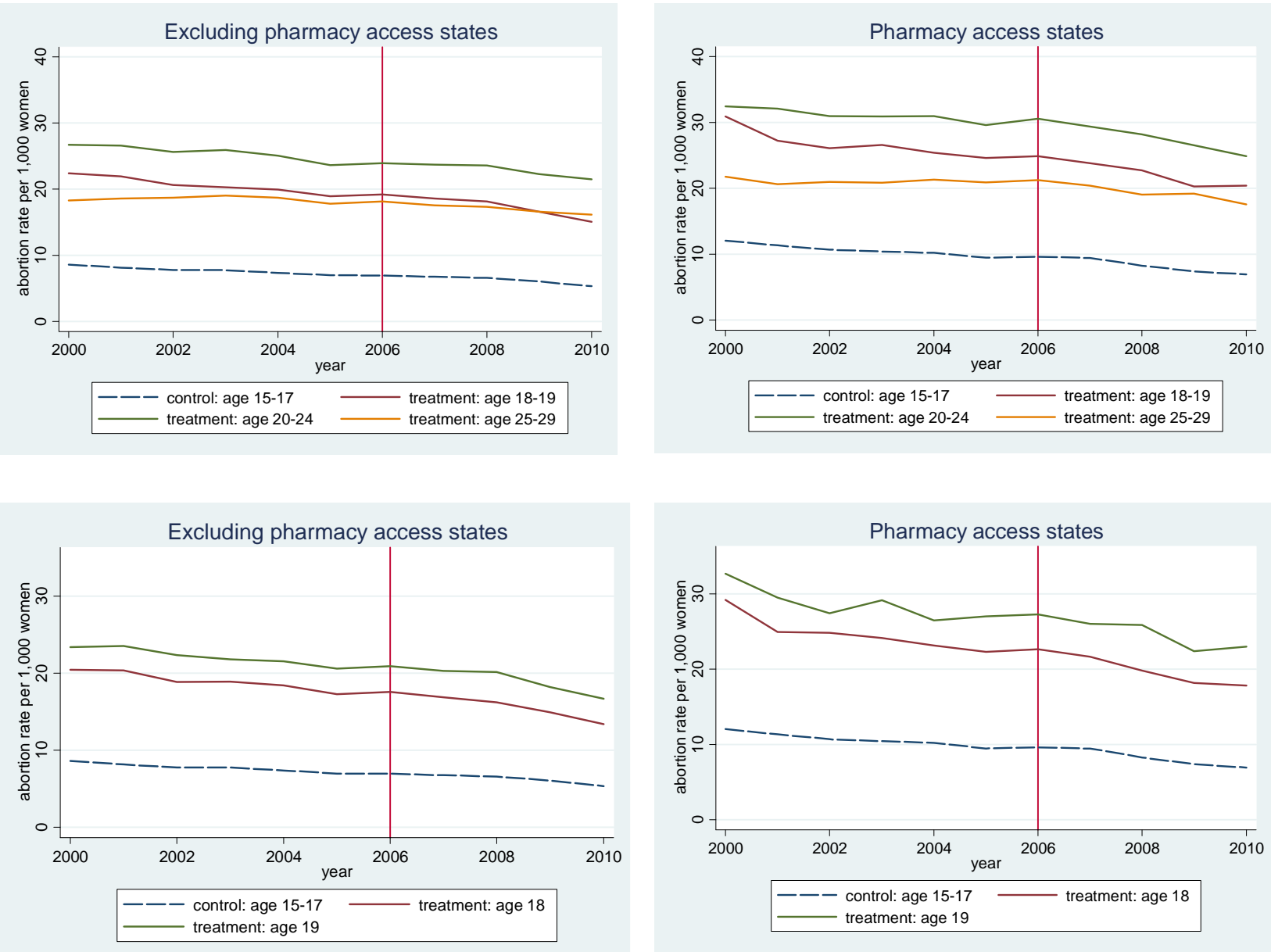

Note: Pharmacy access states are Alaska, Hawaii, Massachusetts, Maine, New Mexico, Vermont, and Washington. California and New Hampshire also had provisions aimed at bypassing the need for a doctor's prescription, but both do not report abortion data. 
FIGURE 2

Event-study estimates for treatment group age 18-19, with $95 \%$ confidence intervals

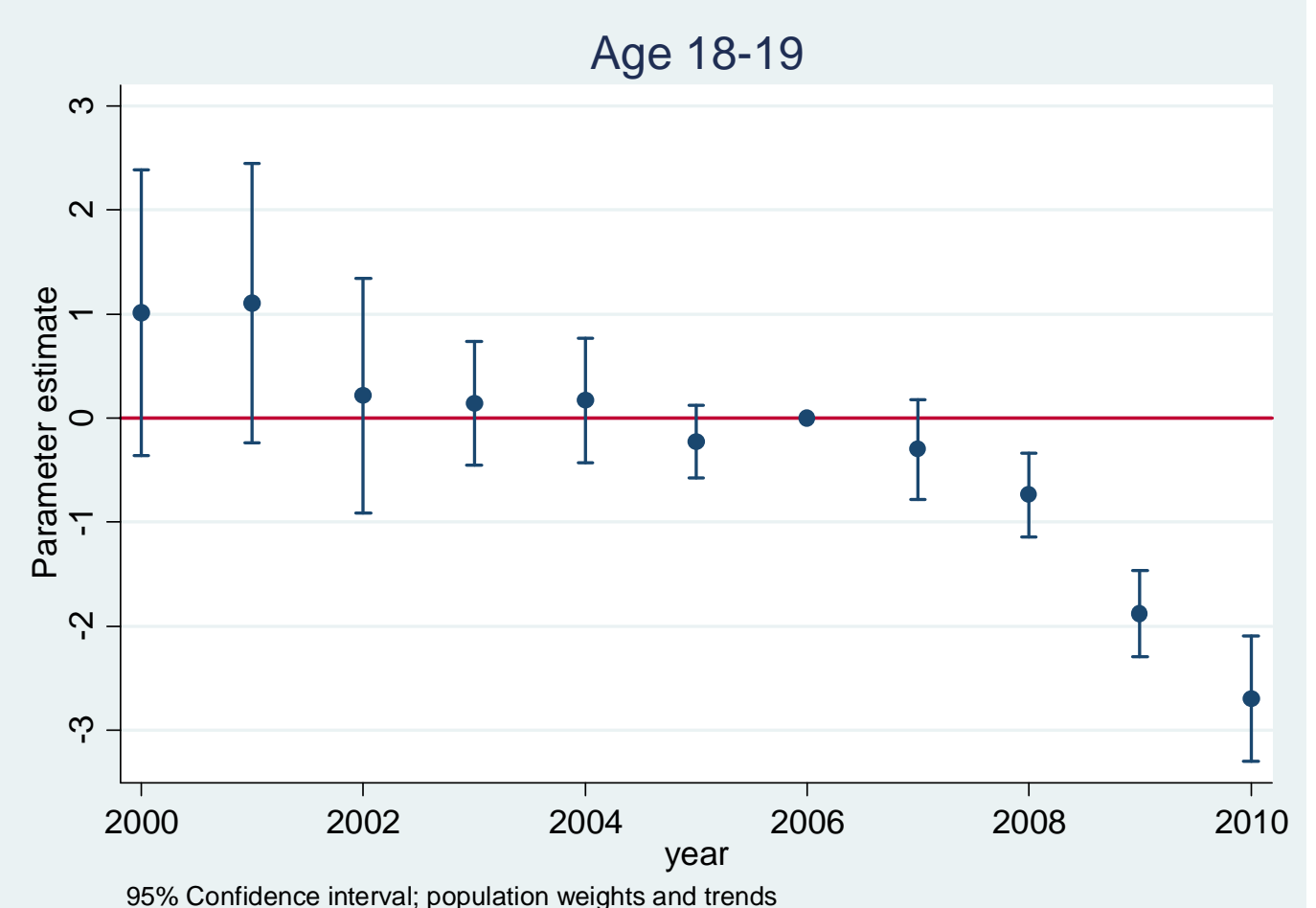

Note: The coefficients shown are for the interaction terms for the 18-19 age group and year dummies (year 2006 is omitted). Control group: women aged 15-17. Dependent variable is the age specific abortion rate per 1,000 women in the corresponding age group. Standard errors are clustered on state. The wild cluster bootstrap-t p-values for the null that the estimate is zero are $0.232,0.004,0.002$, and 0.002 for the interaction of treatment with the $i^{\text {th }}$ year, where year ranges from 2007 to 2010, respectively. Specification also includes a set of state-level socioeconomic characteristics, state and year fixed effects, as well as linear state trends. Observations are weighted by state's female population in the respective age group. 
FIGURE 3

Event-study estimates for treatment group age 20-24, with $95 \%$ confidence intervals

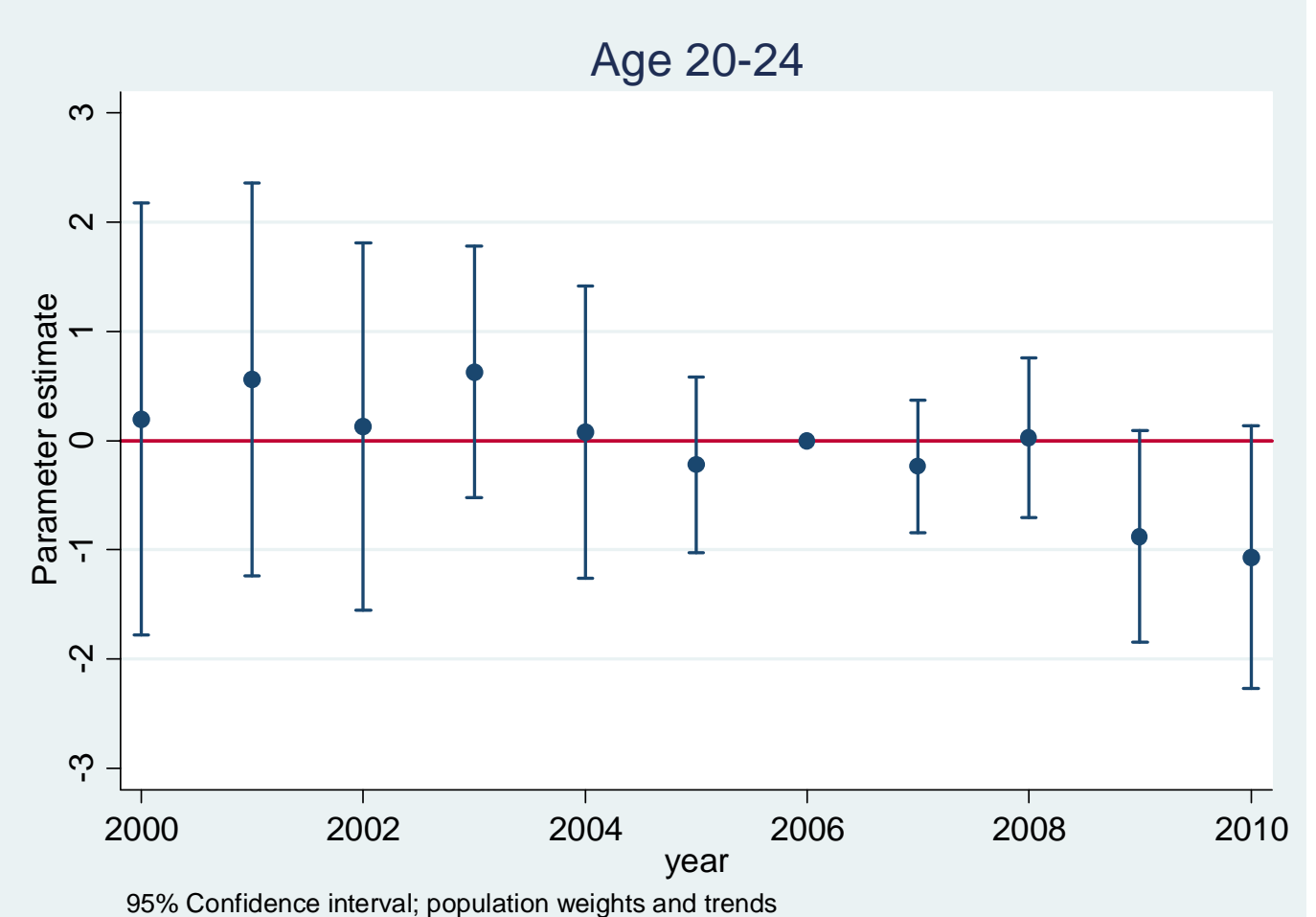

Note: The coefficients shown are for the interaction terms for the 20-24 age group and year dummies (year 2006 is omitted). Control group: women aged 15-17. Dependent variable is the age specific abortion rate per 1,000 women in the corresponding age group. Standard errors are clustered on state. The wild cluster bootstrap-t p-values for the null that the estimate is zero are $0.428,1.000,0.096$, and 0.096 for the interaction of treatment with the $i^{\text {th }}$ year, where year ranges from 2007 to 2010, respectively. Specification also includes a set of state-level socioeconomic characteristics, state and year fixed effects, as well as state linear trends. Observations are weighted by state's female population in the respective age group. 


\section{FIGURE 4}

Event-study estimates for treatment groups age 18 and age 19, with $95 \%$ confidence intervals

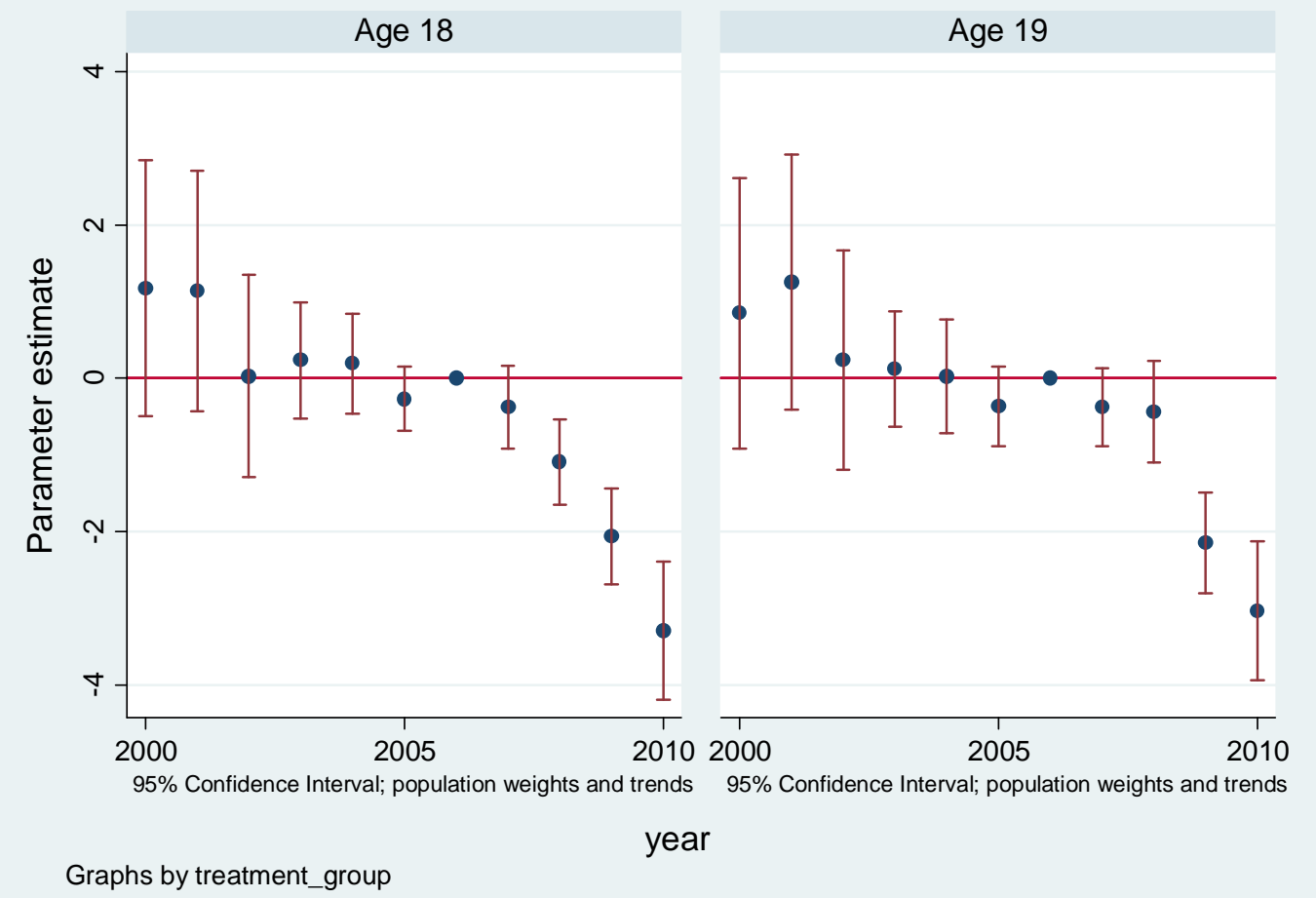

Note: The coefficients shown are for the interaction terms between the indicators for age 18, age 19 and year dummies (year 2006 is omitted). Control group: women age 15 and age 16 . Dependent variable is the age specific abortion rate per 1,000 women in the corresponding age group. Standard errors are clustered on state. The wild cluster bootstrap-t p-values for the null that the estimate is zero are $0.132,0.002,0.002$, and 0.002 for the interaction terms between treatment group “age 18” and the $i^{\text {th }}$ year, where year ranges from 2007 to 2010 respectively. The p-values for the corresponding interaction terms for the treatment group "age 19" are 0.096, $0.174,0.002$, and 0.002 . Specification also includes a set of state-level socio-economic characteristics, state and year fixed effects, as well as state linear trends. Observations are weighted by state's female population in the respective age group. 


\section{FIGURE 5}

Event-study estimates for treatment groups age 18 and age 19, with $95 \%$ confidence intervals, by control group

Panel A: Age 15 control group

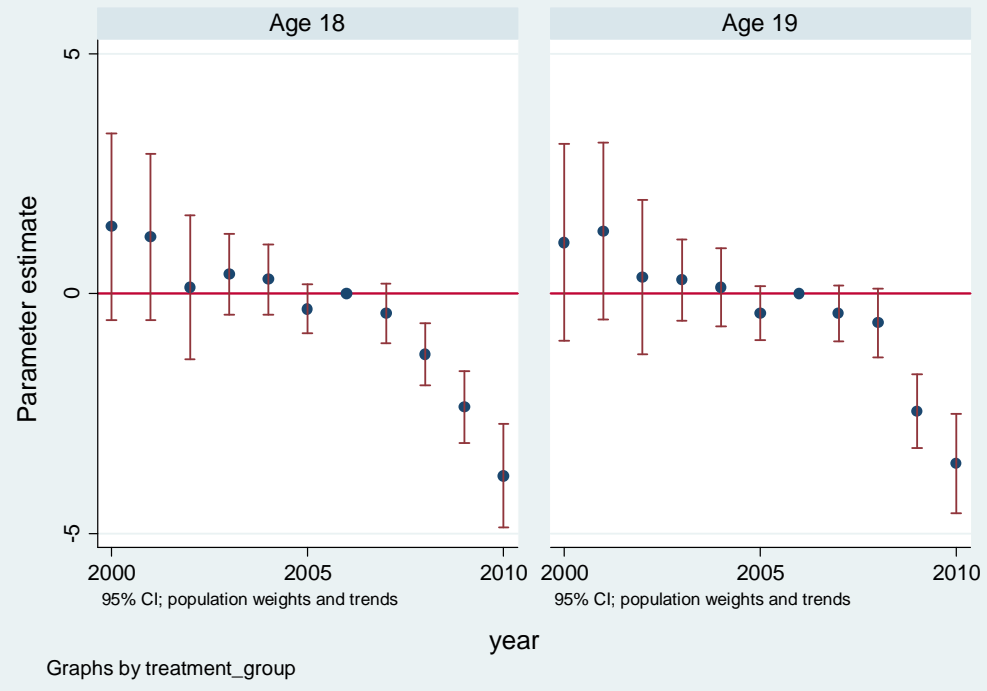

Panel B: Age 16 control group

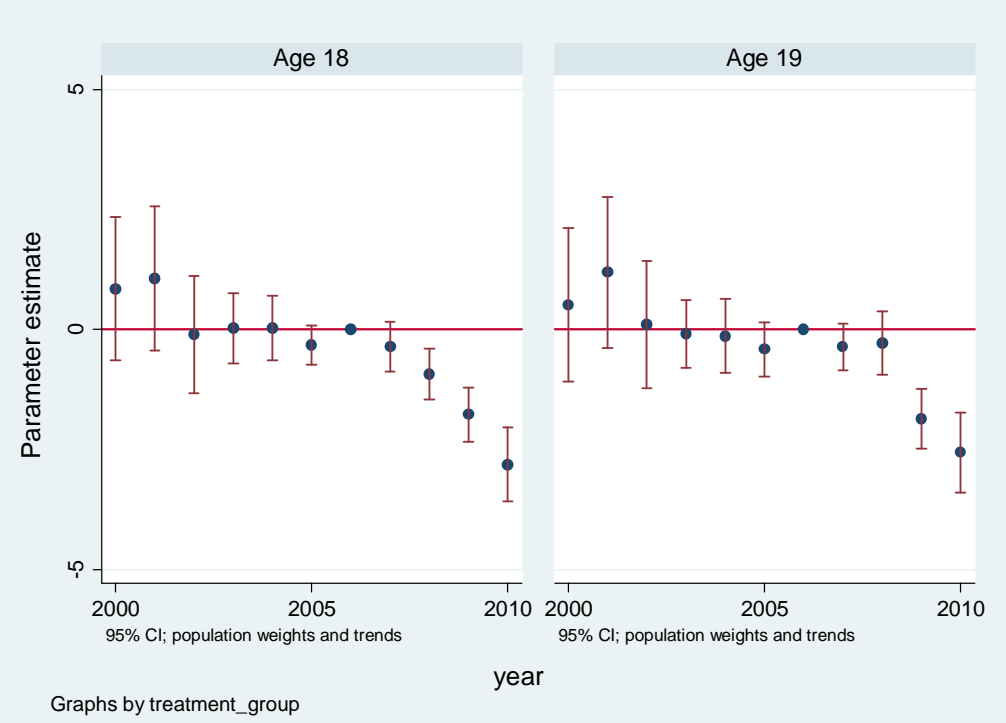

Note: The coefficients shown are for the interaction terms between age group 18, age 19 and year dummies (year 2006 is omitted). Dependent variable is the age specific abortion rate per 1,000 women in the corresponding age group. Standard errors are clustered on state. The wild cluster bootstrap-t p-values for the post FDA policy years for Panel A are: 0.186, 0.002, 0.002, 0.002 for age group 18, and 0.144, 0.102, 0.002, 0.002 for age group 19; for Panel B: 0.140, 0.002, 0.002, 0.002 for age group 18 , and $0.104,0.368,0.002,0.002$ for age group 19 . Specification also includes a set of state-level socio-economic characteristics, state and year fixed effects, and state linear trends. Observations are weighted by state's female population in the respective age group. 
FIGURE 6

Falsification test

Panel A: Interaction terms for age 18-19 (age 15-16 control group)

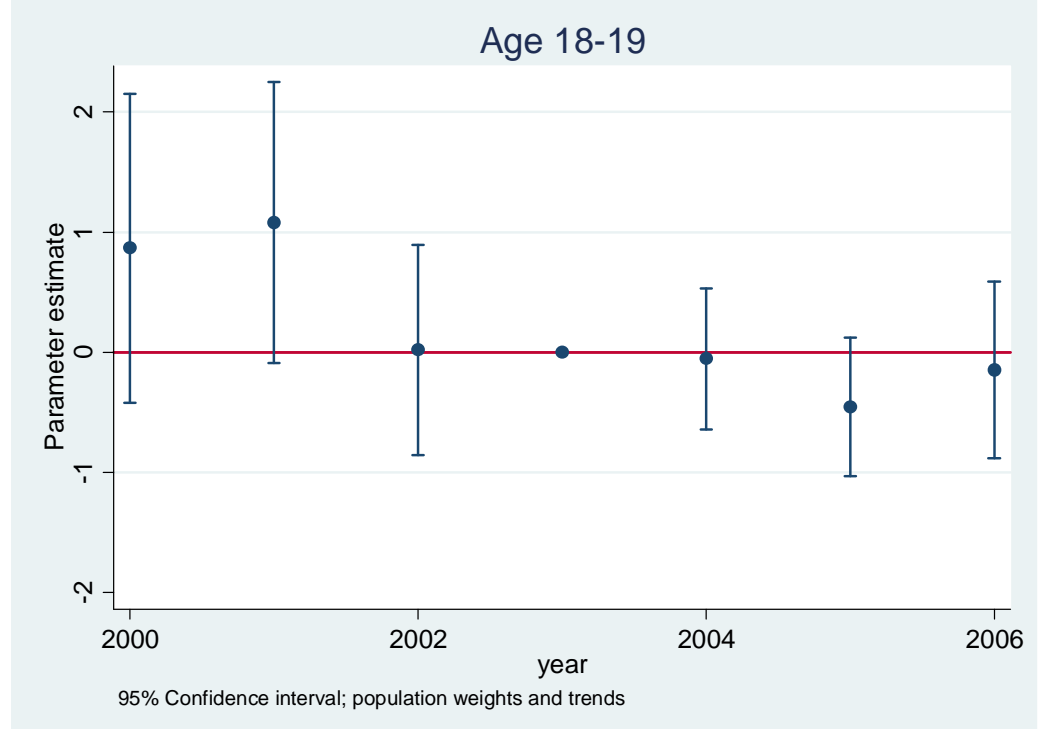

Panel B: Interaction terms for age 18 and 19 (age 15 and age 16 control group)

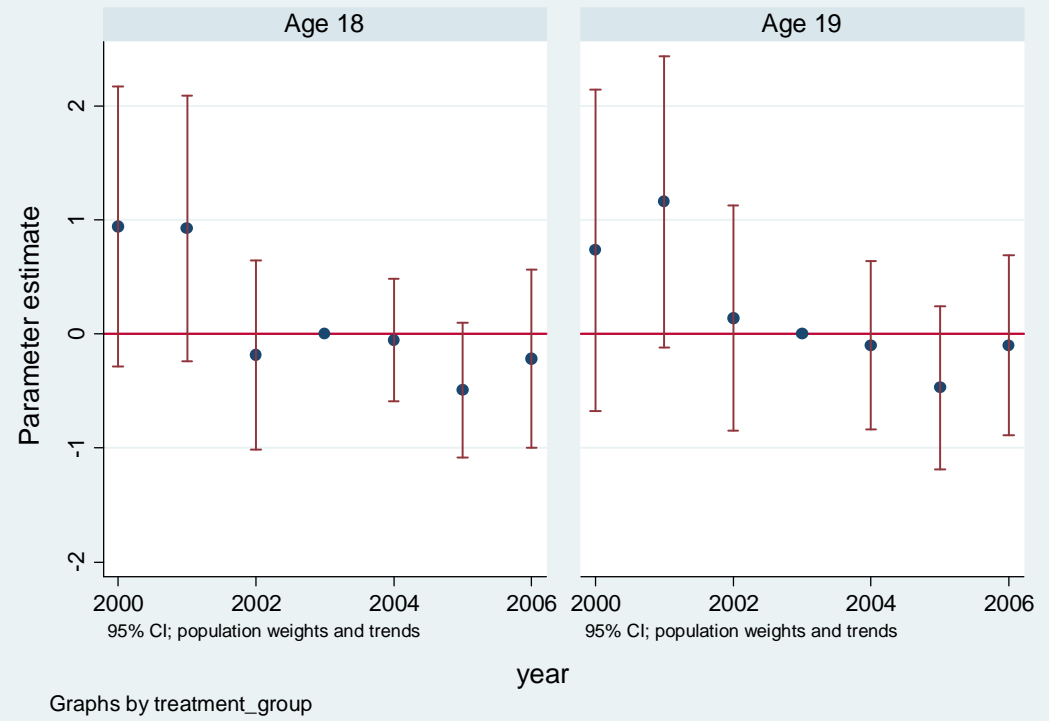

Note: The coefficients shown are for the interaction terms between treatment age group(s) and year dummies (year 2006 is omitted). Dependent variable is the age specific abortion rate per 1,000 women in the corresponding age group. Standard errors are clustered on state.

Specification also includes a set of state-level socio-economic characteristics, state and year fixed effects, and state linear trends. Observations are weighted by state's female population in the respective age group. 
TABLE 1

Descriptive statistics

By single year of age

Mean Std. Dev.

Abortion rate age 15, 2000-2006

$4.13 \quad 2.19$

Abortion rate age 15, 2007-2010

3.37

1.80

Abortion rate age 16, 2000-2006

$\begin{array}{ll}7.52 & 4.32\end{array}$

Abortion rate age 16, 2007-2010

5.92

3.34

Abortion rate age 17, 2000-2006

11.28

6.77

Abortion rate age 17, 2007-2010

9.18

5.47

Abortion rate age 18, 2000-2006

18.83

9.51

Abortion rate age 18, 2007-2010

15.35

Abortion rate age 19, 2000-2006

22.01

7.73

Abortion rate age 19, 2007-2010

18.82

11.26

By age group

$\begin{array}{lll}\text { Abortion rate 15-17, 2000-2006 } & 7.66 & 4.36\end{array}$

Abortion rate 15-17, 2007-2010

6.19

3.50

Abortion rate 18-19, 2000-2006

20.50

10.38

Abortion rate 18-19, 2007-2010

17.09

8.58

Abortion rate 20-24, 2000-2006

25.35

12.48

Abortion rate 20-24, 2007-2010

22.74

10.85

State level socio-economic characteristics

State unemployment rate among females aged 15-19

$15.29 \quad 5.23$

State unemployment rate among females aged 20-24

8.75

3.13

Per capita personal income, 2010\$

$36682.30 \quad 5161.28$

Max monthly benefit for a family of 3 with no income, 2010\$ $415.43 \quad 149.42$

Enforced PI law ${ }^{\text {a }}$

0.81

0.39

Unenforced PI law ${ }^{\text {a }}$

0.09

0.28

Number of unrestricted borders for the PI law ${ }^{\mathbf{b}}$

1.17

1.16

Note: The parental involvement law variable ranges from 0 (no law is enforced) to 1 (the law is enforced). If the law was enforced only for a fraction of a year, then this variable reflects that fraction. The total number of observations for single year abortion rates is 367; for age group 1517 and 18-19 - 368; for age 20-24 - 372. ${ }^{\mathbf{a}}$ Women age 18 and older are assigned 0 (or no enforced PI requirement). ${ }^{\mathbf{b}}$ For women age 18 and older, this variable equals the number of borders. 
TABLE 2

Age-specific abortion rate per 1,000 women

\begin{tabular}{|c|c|c|c|c|c|c|c|c|c|}
\hline & \multicolumn{3}{|c|}{ Panel A } & \multicolumn{3}{|c|}{ Panel B } & \multicolumn{3}{|c|}{ Panel C } \\
\hline & (1) & $(2)$ & (3) & (1) & $(2)$ & (3) & (1) & $(2)$ & (3) \\
\hline age $1819 *$ after2006 & $\begin{array}{l}-1.588^{* *} \\
(0.39)\end{array}$ & $\begin{array}{l}-1.568^{* *} \\
(0.40)\end{array}$ & $\begin{array}{l}-1.756^{* *} \\
(0.34)\end{array}$ & & & & & & \\
\hline age1819*2007 & & & & $\begin{array}{l}-0.668^{+} \\
(0.40)\end{array}$ & $\begin{array}{l}-0.657 \\
(0.41)\end{array}$ & $\begin{array}{l}-0.641 \\
(0.39)\end{array}$ & & & \\
\hline age1819*2008 & & & & $\begin{array}{l}-0.920^{*} \\
(0.40)\end{array}$ & $\begin{array}{l}-0.904^{*} \\
(0.41)\end{array}$ & $\begin{array}{l}-1.077^{* *} \\
(0.36)\end{array}$ & & & \\
\hline age1819*2009 & & & & $\begin{array}{l}-1.948^{* *} \\
(0.45)\end{array}$ & $\begin{array}{l}-1.932^{* *} \\
(0.45)\end{array}$ & $\begin{array}{l}-2.219^{* *} \\
(0.39)\end{array}$ & & & \\
\hline age1819*2010 & & & & $\begin{array}{l}-2.768^{* *} \\
(0.46)\end{array}$ & $\begin{array}{l}-2.754^{* *} \\
(0.46)\end{array}$ & $\begin{array}{l}-3.038^{* *} \\
(0.38)\end{array}$ & & & \\
\hline age2024*2007 & & & & & & & $\begin{array}{c}-0.478 \\
(0.49)\end{array}$ & $\begin{array}{c}-0.480 \\
(0.50)\end{array}$ & $\begin{array}{l}-0.427 \\
(0.52)\end{array}$ \\
\hline age2024*2008 & & & & & & & $\begin{array}{c}-0.308 \\
(0.56)\end{array}$ & $\begin{array}{c}-0.283 \\
(0.57)\end{array}$ & $\begin{array}{l}-0.163 \\
(0.58)\end{array}$ \\
\hline age2024*2009 & & & & & & & $\begin{array}{c}-1.106^{+} \\
(0.58)\end{array}$ & $\begin{array}{c}-1.055^{+} \\
(0.60)\end{array}$ & $\begin{array}{c}-1.061^{+} \\
(0.63)\end{array}$ \\
\hline age2024*2010 & & & & & & & $\begin{array}{c}-1.321^{+} \\
(0.65) \\
\end{array}$ & $\begin{array}{c}-1.300^{+} \\
(0.68) \\
\end{array}$ & $\begin{array}{r}-1.251^{+} \\
(0.70)\end{array}$ \\
\hline Adj. R-squared & 0.896 & 0.908 & 0.944 & 0.899 & 0.909 & 0.945 & 0.886 & 0.889 & 0.937 \\
\hline Population weight & no & no & yes & no & no & yes & no & no & yes \\
\hline Linear trends & no & yes & yes & no & yes & yes & no & yes & yes \\
\hline
\end{tabular}

Note: Standard errors clustered by state are in parentheses. The reported statistical significance is based on the p-values obtained using the wild cluster bootstrap-t method with 1,000 repetitions: ${ }^{* *}$ significant at $1 \%$; ${ }^{*}$ at $5 \%$; ${ }^{+}$at $10 \%$. The number of observations for Panel $\mathrm{C}$ is 740, otherwise 736. Control group: women aged 15-17. Where noted, observations are weighted by state's female population in the appropriate age group. All specifications include a set of state-level characteristics, state fixed effects, and a dummy, AFTER, in Panel A, and year fixed effects in Panels B-C (omitted year 2006). The pre-2007 average abortion rate per 1,000 women aged 18-19 is 20.5; for women aged $20-24$ the rate is 25.4 . 
TABLE 3

Age-specific abortion rate per 1,000 women

\begin{tabular}{|c|c|c|c|c|c|c|}
\hline & \multicolumn{3}{|c|}{ Panel A } & \multicolumn{3}{|c|}{ Panel B } \\
\hline & (1) & (2) & (3) & (1) & (2) & (3) \\
\hline Age $18 *$ after2006 & $-1.874^{* *}$ & $-1.849^{* *}$ & $\begin{array}{l}-2.058^{* *} \\
(038)\end{array}$ & & & \\
\hline Age18*2007 & & & & $\begin{array}{l}-0.888^{*} \\
(0.43)\end{array}$ & $\begin{array}{l}-0.872^{+} \\
(0.43)\end{array}$ & $\begin{array}{l}-0.725 \\
(0.43)\end{array}$ \\
\hline Age18*2008 & & & & $\begin{array}{l}-1.271^{* *} \\
(0.41)\end{array}$ & $\begin{array}{l}-1.251^{*} \\
(0.42)\end{array}$ & $\begin{array}{l}-1.438^{* *} \\
(0.39)\end{array}$ \\
\hline Age18*2009 & & & & $\begin{array}{l}-2.129^{* *} \\
(0.48)\end{array}$ & $\begin{array}{l}-2.109^{* *} \\
(0.48)\end{array}$ & $\begin{array}{l}-2.411^{* *} \\
(0.44)\end{array}$ \\
\hline Age18*2010 & & & & $\begin{array}{l}-3.160^{* *} \\
(0.50)\end{array}$ & $\begin{array}{l}-3.142^{* *} \\
(0.50)\end{array}$ & $\begin{array}{l}-3.638^{* *} \\
(0.48)\end{array}$ \\
\hline Age $19 *$ after2006 & $\begin{array}{l}-1.575^{* *} \\
(0.47)\end{array}$ & $\begin{array}{l}-1.550^{* *} \\
(0.48)\end{array}$ & $\begin{array}{l}-1.812^{* *} \\
(0.44)\end{array}$ & & & \\
\hline Age19*2007 & & & & $\begin{array}{l}-0.627 \\
(0.51)\end{array}$ & $\begin{array}{l}-0.612 \\
(0.52)\end{array}$ & $\begin{array}{l}-0.674 \\
(0.45)\end{array}$ \\
\hline Age19*2008 & & & & $\begin{array}{l}-0.557 \\
(0.51)\end{array}$ & $\begin{array}{l}-0.537 \\
(0.52)\end{array}$ & $\begin{array}{l}-0.732 \\
(0.49)\end{array}$ \\
\hline Age19*2009 & & & & $\begin{array}{l}-2.006^{* *} \\
(0.54)\end{array}$ & $\begin{array}{l}-1.986^{* *} \\
(0.54)\end{array}$ & $\begin{array}{l}-2.442^{* *} \\
(0.49)\end{array}$ \\
\hline Age19*2010 & & & & $\begin{array}{l}-3.053^{* *} \\
(0.55)\end{array}$ & $\begin{array}{l}-3.035^{* *} \\
(0.56)\end{array}$ & $\begin{array}{l}-3.330^{* *} \\
(0.50)\end{array}$ \\
\hline Adj. R-squared & 0.868 & 0.878 & 0.918 & 0.871 & 0.879 & 0.919 \\
\hline Population weight & no & no & yes & no & no & yes \\
\hline Linear trends & no & yes & yes & no & yes & yes \\
\hline
\end{tabular}

Note: Standard errors clustered by state are in parentheses. The reported statistical significance is based on the p-values obtained from the wild cluster bootstrap-t procedure with 1,000 repetitions: ${ }^{* *}$ significant at $1 \%$; ${ }^{*}$ at $5 \%$; ${ }^{+}$at $10 \%$. The number of observations is 1,468 . Where noted, observations are weighted by state's female population in the appropriate age group. All specifications include a set of state-level socio-economic characteristics, state fixed effects, and a dummy, AFTER, in Panel A, or a full set of year fixed effects in Panel B (omitted year 2006). Control group: women aged 15 and women aged 16. The pre-2007 average abortion rate per 1,000 women aged 18 is 18.8; for women aged 19, the rate is 22.0 . 


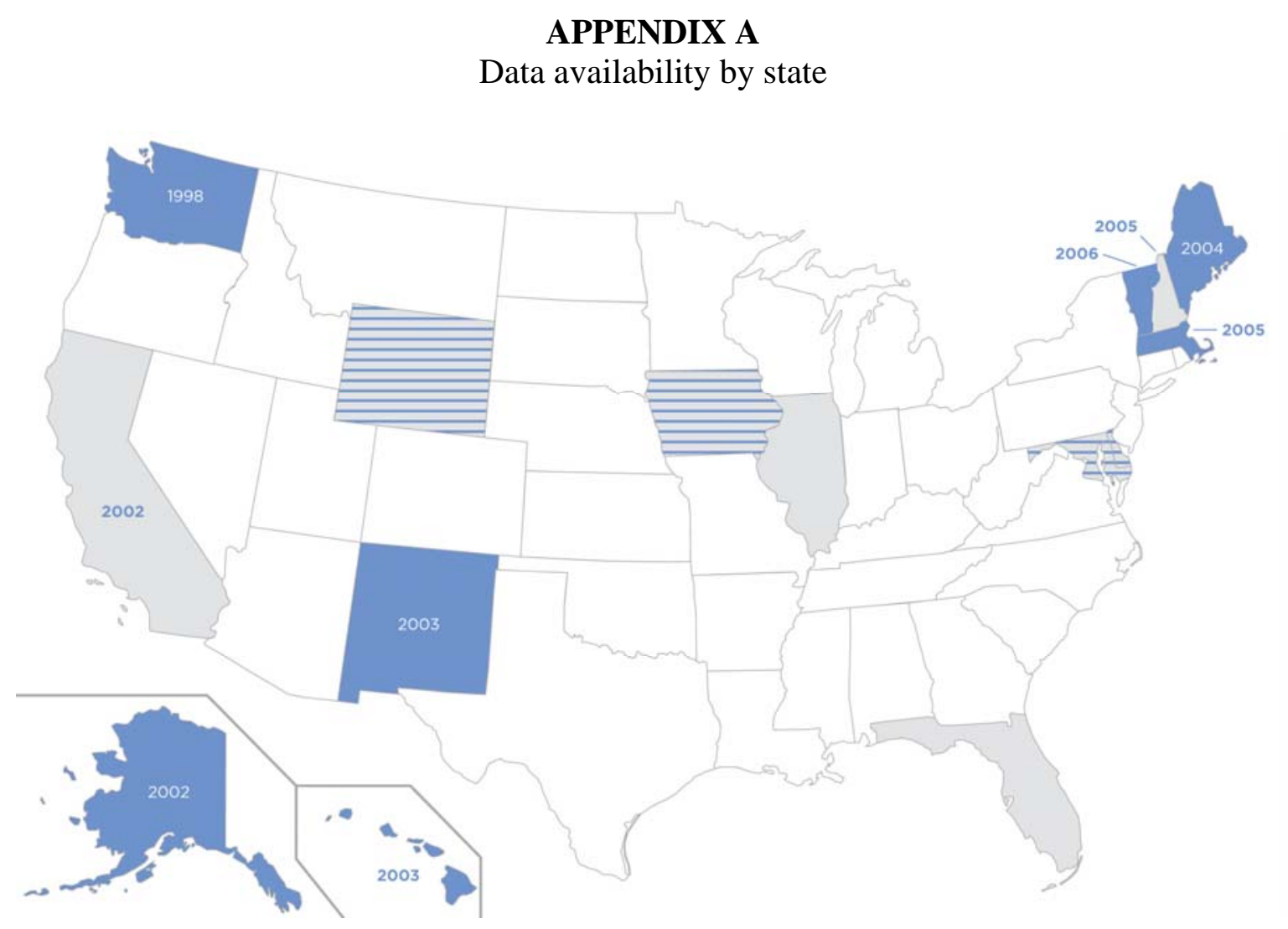

Note: States in grey do not report abortion statistics by age; states in blue are "pharmacy access" states; years indicate a change in the EC pharmacy access law; the stripe pattern indicates that there are some serious issues with the reported data (data for a large number of years is missing, change in reporting standards, etc.). Additionally, data prior to 2003 is missing for Alaska, 2000 for Nevada, 2010 for Vermont, 2005-2009 for Louisiana, and 2003-2004 for West Virginia. 


\section{APPENDIX B}

Robustness checks

Panel A: Standard errors clustered at the age level

\begin{tabular}{lll|ll|ll|ll} 
& \multicolumn{3}{c|}{ Trends; No weights } & \multicolumn{4}{c}{ Trends; Weights } \\
\cline { 2 - 9 } & \multicolumn{2}{c|}{$(1)$} & \multicolumn{2}{|c|}{$(2)$} & \multicolumn{3}{c|}{$(1)$} & \multicolumn{3}{c}{$(2)$} \\
Treatment group & 18 & 19 & 18 & 19 & 18 & 19 & 18 & 19 \\
\hline Treatment*after & $-1.654^{+}$ & -1.355 & & & -1.866 & -1.621 & & \\
& $(0.27)$ & $(0.27)$ & & & $(0.30)$ & $(0.29)$ & & \\
\hline Treatment*2007 & & & -0.338 & -0.219 & & & -0.295 & -0.296 \\
& & & $(0.10)$ & $(0.10)$ & & & $(0.11)$ & $(0.11)$ \\
Treatment*2008 & & $-0.794^{+}$ & -0.221 & & & $-1.031^{+}$ & -0.376 \\
& & $(0.11)$ & $(0.11)$ & & & $(0.14)$ & $(0.13)$ \\
Treatment*2009 & & $-1.571^{+}$ & $-1.589^{*}$ & & & -1.864 & -1.948 \\
& & $(0.18)$ & $(0.18)$ & & & $(0.28)$ & $(0.28)$ \\
Treatment*2010 & & -2.391 & -2.425 & & & -2.852 & -2.595 \\
& & $(0.39)$ & $(0.39)$ & & & $(0.52)$ & $(0.52)$ \\
\hline
\end{tabular}

Note: ${ }^{*}$ significant at $5 \%{ }^{+}$at $10 \%$. The p-values are obtained using the wild cluster bootstrap-t procedure with 1,000 repetitions. Specifications (1) and (2) correspond to equation (1) and (2), respectively. The additional covariates and weights are as described in the note for Table 2 . Control group: women aged 15, 16, and 17. Number of observations in each regression is 1,835.

Panel B: Age-year panel

\begin{tabular}{|c|c|c|c|c|c|c|}
\hline \multirow[b]{2}{*}{ Treatment group } & \multirow{2}{*}{$\begin{array}{c}{(1)^{\mathbf{a}}}^{18-19} \\
\end{array}$} & \multirow{2}{*}{$\begin{array}{c}(2)^{a} \\
20-24\end{array}$} & \multicolumn{2}{|c|}{$(3)^{\mathbf{b}}$} & \multicolumn{2}{|c|}{$(4)^{\mathbf{b}}$} \\
\hline & & & 18 & 19 & 18 & 19 \\
\hline Treatment*after & $\begin{array}{c}-1.920^{+} \\
(0.99)\end{array}$ & $\begin{array}{c}-1.139 \\
(0.79)\end{array}$ & $\begin{array}{c}-2.295^{*} \\
(0.89)\end{array}$ & $\begin{array}{c}-1.993^{*} \\
(0.91)\end{array}$ & & \\
\hline Treatment*2007 & & & & & $\begin{array}{c}-1.304 \\
(1.58)\end{array}$ & $\begin{array}{c}-1.043 \\
(1.58)\end{array}$ \\
\hline Treatment*2008 & & & & & $\begin{array}{r}-1.702 \\
(1.47)\end{array}$ & $\begin{array}{r}-0.988 \\
(1.47)\end{array}$ \\
\hline Treatment*2009 & & & & & $\begin{array}{r}-2.561^{+} \\
(1.40)\end{array}$ & $\begin{array}{r}-2.436^{+} \\
(1.39)\end{array}$ \\
\hline Treatment*2010 & & & & & $\begin{array}{c}-3.614^{* * *} \\
(1.23)\end{array}$ & $\begin{array}{c}-3.506^{* *} \\
(1.22)\end{array}$ \\
\hline $\mathrm{N}$ of observations & 22 & 22 & & & & \\
\hline Adj. R-square & 0.972 & 0.989 & & & & \\
\hline Control group & $15-17^{c}$ & $15-17^{c}$ & & & & \\
\hline
\end{tabular}

Note: ${ }^{* *}$ significant at $1 \%$; ${ }^{*}$ at $5 \%$; ${ }^{+}$at $10 \%$. Robust standard errors are in parentheses. Only the estimates for the interaction terms are reported. Regressions weighted by female population produce qualitatively similar point estimates. ${ }^{\text {a }}$ Other controls are dummies for treatment group and "AFTER". ${ }^{\mathbf{b}}$ Other controls are dummies for each treatment group and year. ${ }^{\mathbf{c}}$ An alternative control group, women aged 15-16, yields slightly larger estimates with smaller standard errors. 